\title{
Elementos formales de la felicidad. Una lectura no comprensiva de Aristóteles
}

David Santiago Mesa Díez

Universidad de Antioquia, Colombia

(c) $\underset{\mathrm{Br}}{\mathrm{i}}$ 


\title{
Elementos formales de la felicidad. Una lectura no comprensiva de Aristóteles*
}

Resumen: a lo largo de este artículo presentaré los elementos que conforman la idea de la felicidad para Aristóteles y al final presentaré algunas proposiciones epilogales sobre dicha idea como un fin no comprensivo, es decir, sin suscribir la posición que aquel adoptó al identificar la vida contemplativa de los filósofos y la experiencia política en la polis griega como los prototipos idóneos de su descripción de la idea de felicidad. Esto con el fin de apreciar qué elementos nos puede aportar el estagirita para pensar un concepto de felicidad aplicable a las circunstancias de los seres humanos que habitamos las sociedades contemporáneas.

Palabras clave: felicidad, actividad, virtud, proyecto de vida.

\section{Formal Elements of Happiness. A non-comprehensive reading of Aristotle}

\begin{abstract}
I will present the elements of the Aristotle's idea of happiness. In the last part, I will present some epilogues proposals on this idea as a noncomprehensive purpose, i.e., without endorsing the position that he adopted to identify the contemplative life of philosophers and political experience in the Greek polis as the prototypes suitable for the idea of happiness. This in order to appreciate the elements that the Stagirus's philosopher can provide for us to think a concept of happiness applicable to the circumstances of human beings on contemporary societies.
\end{abstract}

Keywords: happiness, activity, virtue, life project.

Fecha de recepción: 2 de febrero de 2017

Fecha de aceptación: 19 de junio de 2017

Forma de citar (APA): Mesa Díez, D. (2017). Elementos formales de la felicidad. Una lectura no comprensiva de Aristóteles. Revista Filosofía UIS, 16(2), doi http://dx.doi.org/10.18273/ revfil.v16n2-2017001

Forma de citar (Harvard): Mesa Díez, D. (2017). Elementos formales de la felicidad. Una lectura no comprensiva de Aristóteles. Revista Filosofía UIS, 16(2), 19-42.

David Santiago Mesa Díez: colombiano. Magíster en Filosofía. Profesor del Instituto de Filosofía de la Universidad de Antioquia. Miembro del Grupo de Investigación en Filosofía Política GIFP.

Correo electrónico: david.mesa@udea.edu.co

\footnotetext{
* Artículo de reflexión derivado de un trabajo de investigación a nivel de maestría finalizado en el año 2016 y titulado: Felicidad y Política: argumentos desde Aristóteles, Mill y Rawls. Investigación adscrita al Grupo de Investigación de Filosofía Política (GIFP) en la línea «Teorías de la Justicia y de la Igualdad». Para la elaboración de este artículo las conversaciones y sugerencias bibliográficas del profesor Jairo Iván Escobar Moncada fueron importantes, por eso expreso mi gratitud a tan destacado profesor, quien recientemente falleció (11-6-2017) q.e.p.d.
} 


\section{Elementos formales de la felicidad. Una lectura no comprensiva de Aristóteles}

A lo largo de este artículo presentaré los elementos que conforman la idea de la felicidad para Aristóteles y al final haré algunas proposiciones epilogales sobre dicha idea como un fin no comprensivo, es decir, sin suscribir la posición que aquel adoptó al identificar la vida contemplativa de los filósofos y la experiencia política en la polis griega como los prototipos idóneos de su descripción de la idea de felicidad. El objetivo es apreciar qué elementos nos aporta el estagirita para pensar un concepto de felicidad aplicable a las circunstancias de los seres humanos que habitamos las sociedades contemporáneas.

He hecho el intento de ser fiel al autor y extraer sus argumentos sustanciales de acuerdo a como él los presenta en diferentes apartes de tres de sus libros de filosofía práctica, a saber: Ética Nicomáquea (EN), Ética Eudemia (EE) y Política (Pol). La dificultad que encierra este ejercicio consiste en que Aristóteles es un autor clásico y sobre sus ideas se han escrito infinidad de libros e interpretaciones, que no siempre simplifican la labor de comprensión sino que muchas veces la diversifican y la hacen más compleja. Por esta razón he decidido recurrir a los intérpretes solo en lo estrictamente necesario y exponer, en la medida de lo posible, la forma en que Aristóteles presenta directamente sus ideas.

\section{Notación sobre el significado asumido para la palabra eudaimonía}

«Felicidad» suele ser la traducción que generalmente se da al término griego eudaimonía, transliteración de aquel que Aristóteles utiliza en el tratamiento que le atribuimos sobre el tema de la felicidad. Al inicio de su Ética Nicomáquea Aristóteles dice que, en su sentido más general, eudaimonía consiste tanto en vivir bien como en obrar bien (EN I.4.1095a19); igualmente, al inicio de su Ética Eudemia Aristóteles realiza una acotación similar y afirma que eudaimonía parece ser para todos el significado de lo que implica vivir dichosa y honestamente (EE I.1.1214a30). En nuestros días existe una discusión académica sobre la traducción 
más adecuada para eudaimonía', se sugiere traducir este término con expresiones como "vida lograda", "vida que vale la pena vivir", "vida cumplida" o "vida máximamente satisfecha". Con todo, el filósofo griego utiliza la misma palabra (eudaimonía) tanto para referirse al uso común del término al inicio de sus dos obras éticas (cuando habla del modo en que la gente la utiliza), como al final de las mismas cuando ya ha expuesto su concepción filosófica al respecto. Esto indica que podemos asumir que el tema que Aristóteles aborda es esencialmente el mismo que implica en nuestros días la pregunta por la felicidad ${ }^{2}$, siempre que tengamos en cuenta algunas restricciones para evitar la degradación significante. Por eso trataré de acercarme a las elaboraciones del filósofo procurando extraer lo que hay de permanente en ellas de acuerdo a una lectura analítica de los textos filosóficos ${ }^{3}$. Además, la homologación que asumiré de la palabra eudaimonía con nuestra palabra felicidad no perderá de vista el carácter que Aristóteles le atribuye ${ }^{4}$ : primero como algo estable, no fluctuante como los sentimientos sino como una

\footnotetext{
1 "Eudaimonía" es una palabra compleja que tiende a perder su sentido religioso y su dimensión práctica cuando es traducida como "felicidad" o "bienestar". Eudaimonía es una actividad cuyo fin (telos) no se encuentra al margen de la acción, por lo que Aristóteles la relaciona con la "energeia" y no con la "entelequia" (acto plenamente cumplido), como veremos al avanzar en la exposición del primero de los elementos formales que identifico con la idea aristotélica de felicidad. Cuando se la piensa a la luz de su morfología se puede reconocer que involucra un cierto tipo de relación con el "dáimon", una que es buena dado el prefijo "eu" (que significa bueno) y que es una condición de posibilidad para actuar correctamente. Siendo así, cabe sostener que la eudaimonía tiene un sentido eminentemente práctico: desde lo ético puesto que indica una manera de ser consigo mismo, y desde lo político en tanto la acción siempre se realiza en una comunidad; también es político si se tiene en cuenta que para los griegos del siglo IV a. C. no existía una separación tajante entre religión y política, motivo por el cual el dáimon podría ser considerado como una figura política que determina el tipo de relación tanto del individuo consigo mismo como del individuo con su comunidad. En este orden de ideas, para entender el sentido de la palabra "eudaimonía" en el contexto griego del tiempo en que vivió Aristóteles hay que considerar dos cosas: i) el sentido de la palabra "dáimon" y el prefijo "eu" que significa bueno, de buena cualidad y que en eudaimonía se puede pensar como una buena manera de ser con el dáimon y ii) la dimensión religiosa de la palabra, así como la estrecha relación religión-política. Para ampliaciones al respecto remitirse a Chantraine (1977, p. 246, 383, 388); Snell (2007, p. 281) y Luri (2011, pp. 76-78).

${ }^{2}$ En nuestros días la felicidad es un tema bastante ambiguo. Hay muchas personas que la consideran como algo obvio y de fácil acceso, como también las hay que prefieren andar con cautela y admiten que es algo incierto y difícil de conseguir. Aristóteles reconoció este tipo de predisposiciones y anunció la complejidad del tema cuando afirmó lo siguiente: "no es fácil juzgar correctamente acerca de muchas otras cuestiones, pero sobre todo acerca de aquella que les parece a todos que es la más fácil y que conocerla es propio de cualquiera: cuál de las cosas en las que consiste el vivir (felizmente) es preferible, y con cuál uno tendría saciado el deseo si la consiguiera" (EE I.5.1215b20).

${ }^{3}$ Con este tipo de lectura me refiero a la que Bobbio identifica como tal en su texto 'Las razones de la filosofía política' y que describe como aquella que busca resaltar el valor de la elaboración y construcción doctrinal que realiza el filósofo con la intención de que sea válida para todo tiempo y lugar (Cf. 2003, pp. 108-109).

${ }^{4}$ En lo que sigue traduciré entonces eudaimonía directamente como felicidad. Esto significa que seguiré fielmente la aparición de la palabra eudaimonía en el texto griego y la traduciré invariablemente como felicidad.
} 
condición que permanece; segundo como algo objetivo, de otra manera nadie sabría nunca si es verdaderamente feliz; tercero como algo universal, algo que ha de ser similar en todos los seres humanos aunque no necesariamente idéntico; y cuarto como algo que tiene una cierta relación con lo divino, en la medida en que hace parte de aquello que es mejor en nosotros ${ }^{5}$.

\section{Los elementos formales de la idea de felicidad para Aristóteles}

En el tratamiento que el filósofo hace sobre la idea de la felicidad, es posible separar sus reflexiones en dos partes: las formales y las materiales ${ }^{6}$. Las primeras consisten en su intento de indicar los elementos estructurales que debe tener todo aquello que sea reconocido como felicidad; las segundas en lo que el filósofo, desde su contexto experiencial concreto y específico, explica como aquello que más se acerca al cumplimiento de los elementos que estructuralmente se han identificado con ella.

Aristóteles establece que la felicidad puede entenderse estructuralmente de la siguiente manera: actividad de acuerdo con la virtud que debe cumplir con dos condiciones: primero, debe ser perfecta y, segundo, debe ser auto-suficiente (EN I.7.1097a15-b21). Lo anterior es una descripción que expone los elementos formales de la idea de felicidad para Aristóteles, los cuales son cuatro en total, a saber: (1) la felicidad cumple las características de una actividad, (2) está emparentada con la virtud, (3) es perfecta y (4) es autosuficiente. Desarrollemos cada uno de estos elementos.

\section{La felicidad es una actividad}

Para Aristóteles «actividad» (energeia) "es algo que se hace, y no algo de que se dispone desde luego como una cosa que se posee" (EN IX.9.1169b30), por eso él concibe la felicidad como un actuar y no como el hecho de poseer cosas (Cf. EN I.7.1098b30). No puede entonces nacerse con ella porque tampoco es un atributo. Para Aristóteles los atributos y las posesiones no producen nada por sí mismos, aislados o sin nadie que los use simplemente permanecen inmóviles y se van deteriorando con el tiempo. Solo aquellos que actúan pueden alcanzar la felicidad, pues toda suerte de atributo o de posesión solo resulta útil como un medio para ser feliz. A este respecto es bien conocida la opinión del filósofo griego frente a la riqueza, ante la que afirma: "es evidente que la riqueza no es el bien que buscamos, pues solo es útil para otras cosas" (EN I.5.1096a5).

\footnotetext{
Adopto estas cuatro características de la lectura de Michael Pakaluk a la Ética Nicomáquea (2005, p. 48).

${ }^{6}$ Esta forma de operar del filósofo es algo reconocido por muchos de sus intérpretes. Referencias específicas sobre el tema pueden encontrarse en Vigo (2006, pp. 190-200) y Roche (1991, p. 51).
} 
Paralelamente a esto, Aristóteles sostiene que la felicidad no puede ser tampoco una facultad, un estado, una condición del carácter o un modo de ser (el término griego para todas estas expresiones es héxis, que algunos traducen también como hábito o disposición), ya que ninguna de estas cosas cobra relevancia más que cuando es puesta en acción. La clave para comprender a Aristóteles aquí queda revelada si nos preguntamos lo siguiente: ipuede decirse que una persona es feliz porque tiene facultades, está en buen estado o posee un modo de ser que consideramos bueno? Aristóteles no dudaría en dar un no rotundo como respuesta, explicaría que llamamos feliz al hombre por sus acciones y obras y no simplemente porque permanece inactivo (Cf. EN I.12.1101b15), y tal como no podemos darle la corona al atleta olímpico que está bien entrenado pero no compite ni gana, tampoco podemos llamar feliz a quien no realiza acciones que comportan felicidad. Dice expresamente el filósofo:

Hay no poca diferencia entre poner el máximo bien [la felicidad] en una posesión o un uso, en un hábito o una actividad. Porque el hábito que se posee puede no producir ningún bien, como en el que duerme o está de cualquier otro modo inactivo, mientras que con la actividad esto no es posible, ya que esta actuará necesariamente y actuará bien. Del mismo modo que en los Juegos Olímpicos no son los más hermosos ni los más fuertes los que alcanzan la corona, sino los que compiten (pues entre estos algunos vencen), así también las cosas hermosas y buenas que hay en la vida solo las alcanzan los que actúan certeramente; y la vida de estos es agradable por sí misma (EN I.8.1098b33-99a6).

De acuerdo a este razonamiento, Aristóteles considera que solamente las acciones que pueden desprenderse de los estados o de la buena condición de las personas (héxis), son las verdaderas fuentes de la felicidad. Ser felices no radica en el hecho de poseer cosas o de permanecer estáticos en determinada condición o estado del carácter, se trata es de actuar de acuerdo a lo que todo esto permite.

Ahora bien, el énfasis que Aristóteles atribuye a la acción como el primer elemento formal de la felicidad, está conectado con el hecho de que los seres humanos son los únicos seres que pueden actuar para ser felices (Cf. EN I.9.1100a1-10). A diferencia de los demás animales los humanos son los únicos con la capacidad para la libre elección, lo cual les permite realizar acciones deliberadas y no solo aquellas que responden automáticamente a los estímulos externos (Cf. EN VI.2.1139a19). Aristóteles lo explica en los siguientes términos: "En los seres inanimados el principio de la acción es simple, mientras que en el hombre es múltiple [...]. De modo que, respecto de los demás animales, lo forzoso es simple, como respecto a los seres inanimados -pues no tienen [en oposición] razón y deseo, sino que viven solamente según su deseo-, mientras que en el hombre ambos están presentes en una cierta edad" (EE II.8.1224a22). 
En consecuencia, como la felicidad está determinada en su génesis por la combinación entre la razón y el deseo, que son condición de posibilidad para la libre elección en los seres humanos, ningún estado o héxis puede producir felicidad en sí mismo. Por lo tanto, el hecho de poseer riquezas, estar sanos o tener las virtudes moralmente más deseadas no conducen por sí mismas a la felicidad. Lo anterior acentúa un hecho antropológico que para Aristóteles es claro: el ser humano no es un ser que simplemente acumula sino que se ve obligado a proveerse de ciertas cosas para poder vivir, para poder actuar. Lo importante no son las cosas sino las actividades que se realizan por medio de ellas; la vida humana es entonces actividad y la felicidad es un tipo concreto de actividades que se desarrollan dentro de esta (Cf. EE II.1.1219b2).

Ahora, no a cualquier combinación entre razón y deseo va a concederle Aristóteles las actividades que contribuyen a la felicidad. Si bien es válido afirmar que toda actividad envuelve necesariamente la combinación entre razón y deseo, esto no significa que cualquier actividad es génesis de lo que Aristóteles entiende por felicidad. De acuerdo al filósofo griego, la felicidad solamente está emparentada con aquellas actividades que se realizan de acuerdo con la virtud y estas han de ser las que deben ser elegidas.

\section{La felicidad es algo emparentado con la virtud}

Inicialmente el filósofo griego hace notar que la felicidad debe ser actividad relacionada con las cosas que los seres humanos pueden elegir libremente, pero luego indica que no cualquier elección conduce a la felicidad sino solo aquellas en las que se alcanza una adecuada combinación entre la razón y el deseo. "La virtud -dice Aristóteles- es una disposición relativa a la elección y la elección es un deseo deliberado, el razonamiento tiene que ser verdadero y el deseo recto para que la elección sea buena, y tiene que ser lo mismo lo que la razón diga y lo que el deseo persiga" (EN VI.2.1139a23). De este modo, la felicidad está conectada con actividades que conllevan un uso de la razón de acuerdo con la verdad y en las que el deseo está rectamente orientado. En qué consisten estas actividades y cómo es posible lograrlas requiere explorar un poco más las elaboraciones de Aristóteles.

Lo primero que debe indicarse es que para el filósofo griego todos los elementos desiderativos que poseen los seres humanos, y en general todas sus emociones y sentimientos, pueden escuchar y obedecer a la razón, aun cuando la naturaleza de estos sea propiamente irracional (Cf. EN I.13.1102b30-03a6). Aristóteles explica que existen dos formas en las que se da la interacción de la razón y el deseo. Por un lado, están las acciones que ponen en un primer plano al deseo, pero pueden recibir una adecuada orientación de la razón. Por otro lado, están las acciones en las que la razón es preminente al deseo, el cual solo cumple un rol 
motivador pero no interviene a que estas se realicen con propiedad. Respecto a las primeras, Aristóteles dice que dan lugar a las virtudes éticas o del carácter, que consisten en acostumbrar los deseos a escuchar la razón, lo cual requiere de una práctica constante; aquí, por ejemplo, aparecen virtudes como la moderación y la amabilidad, entre otras, ya que uno se hace moderado y amable cuando desea actuar moderada y amablemente, para lo cual la razón debe orientar al deseo a que prefiera estas acciones sobre otras. Respecto a las segundas, Aristóteles explica que gracias a la disciplina, el adiestramiento y la ayuda de los maestros pueden ir naciendo las virtudes intelectuales, que son concretamente la ciencia, el arte, el intelecto, la sabiduría y la prudencia, todas ellas dependientes del papel protagónico de la razón y en donde el deseo solo inclina al ser humano a elegir unas con predilección a otras.

Puestas así las cosas, para Aristóteles la felicidad se logra cuando se elige actuar con virtud y esto significa, por un lado, lograr que nuestros deseos sean inteligentes mediante la acertada orientación de la razón y, por otro lado, que nuestra inteligencia sea deseosa para poder conducir mejor y con mayor satisfacción nuestras actividades intelectuales (Cf. EN VI.2.1139b4).

Ahondando uno a uno en estos dos tipos de virtudes, hagámoslo primero con las éticas o del carácter. Respecto a estas Aristóteles explica lo siguiente: dado que en las acciones en las que se manifiesta el deseo existe un exceso, un defecto y un término medio, la naturaleza propia de la virtud ética ha de ser aquella que ni se excede ni se queda corta, es decir, aquella que le permite al ser humano llevar a cabo sus acciones sin agotarse. Para Aristóteles la naturaleza de la virtud ética es entonces la justa proporción, es decir, el punto medio entre un exceso y un defecto en lo que se refiere al deseo.

Sin embargo, la comprensión de la virtud ética como término medio cuenta todavía con algunos otros elementos. Miremos: La definición que da Aristóteles sobre el término medio reza, con más exactitud, de la siguiente manera: "Llamo término medio de una cosa al que dista lo mismo de ambos extremos, y este es uno y el mismo para todos; y en relación con nosotros, al que ni excede ni se queda corto, y este no es ni uno ni el mismo para todos" (EN II.6.1106a27). De lo anterior se sigue que para Aristóteles existen dos clases de término medio, por un lado está el de las cosas, que siempre es el mismo, "por ejemplo, si diez es mucho y dos es poco, se toma el seis como término medio en cuanto a la cosa, pues excede y es excedido en una cantidad igual" (EN II.6.1106a32); y por otro lado está el término medio relativo a nosotros, en el que se centra la virtud ética, "pues si para uno es mucho comer diez minas de alimentos, y poco comer dos, el entrenador no prescribirá seis minas, pues probablemente esa cantidad será mucho o poco para el que ha de tomarla: para Milón [atleta varias veces vencedor de los Juegos Olímpicos] poco; para el que se inicia en los ejercicios corporales, mucho" (EN II.6.1106b1). 
De esta manera, Aristóteles deja claro que el justo medio no está determinado para nadie de antemano, puesto que el justo medio que yo considero justo para mí puede no serlo para otra persona. Surge entonces una pregunta obligada ¿cómo puede alguien llegar a determinar mejor cuál es el justo medio relativo a sí mismo, en lo que se refiere al actuar de acuerdo con las virtudes éticas?

El acento sobre el término medio relativo a sí mismos hay que buscarlo haciendo referencia a otra cosa. En la Ética Eudemia Aristóteles afirma que "en todo el término medio relativo a nosotros es lo mejor, porque esto es lo que la acción y la razón ordenan" (EE II.3.1220b28). Ahora bien, ¿qué es entonces lo que la acción y la razón ordenan?

Para poder responder a las preguntas que han quedado planteadas, es necesario introducir ahora las virtudes intelectuales. Cabe recordar que para Aristóteles las actividades en las que aparece la razón de forma eminente sobre el deseo son las que dan origen a las virtudes intelectuales, que son el arte, la ciencia, la prudencia, la sabiduría y el intelecto. Las virtudes intelectuales se dividen a su vez en dos partes y esta división toma sus fundamentos de acuerdo a la función que la razón desempeña respecto a los objetos a los que se aplica. Aristóteles llama teórica a la razón cuando se aplica al conocimiento de las cosas inmutables y necesarias, e identifica con esta el desarrollo de las virtudes de la ciencia, la sabiduría y el intelecto. Por otro lado, Aristóteles llama práctica a la razón que le corresponde saber sobre las cosas particulares, en tanto contingentes y variables, e identifica dentro de esta el desarrollo de las virtudes del arte y la prudencia. A la prudencia y no al arte es a la que corresponde juzgar frente a las acciones concretas, pues el arte tiene por objeto la producción y "la disposición racional apropiada para la acción es cosa distinta de la disposición racional para la producción" (EN VI.4.1140a4). La idea que subyace aquí en el pensamiento aristotélico es que el influjo de la prudencia en el ser humano no produce algo cuyo resultado es externo a la persona que lleva a cabo las acciones, como en las artes, sino que es más bien algo anímico que lo impulsa a actuar de determinada manera, en síntesis, la prudencia conduce a la acción y no a la producción. En este orden de ideas, "la prudencia -dice Aristóteles- es un modo de ser racional verdadero y práctico, respecto de lo que es bueno y malo para el hombre" (EN VI.5.1140b2). Lo cual es lo mismo que decir que la prudencia corresponde a lo que el filósofo denomina como recta razón (orthos logos).

Por lo tanto, si volvemos a la referencia que hacíamos más arriba sobre la Ética Eudemia, en donde Aristóteles afirma que "en todo el término medio relativo a nosotros es lo mejor, porque esto es lo que la acción y la razón ordenan" resulta, por consiguiente, que el justo medio relativo a nosotros es lo que la prudencia nos enseña con respecto a los deseos y las acciones. 
En contraste con lo anterior, bien puede suceder que los modos de ser o las virtudes éticas, que se desarrollan en los seres humanos por acostumbrarse siempre a obedecer a lo que la recta razón ordena, surjan por naturaleza o se desarrollen como si fueran atributos innatos -como algunos que desde el nacimiento son justos, moderados o valientes-; sin embargo, dice Aristóteles, "si el hombre adquiere la razón, hay una diferencia en la actuación, y el modo de ser que solo tiene una semejanza con la virtud, será entonces la virtud por excelencia" (EN VI.13.1144b13). Por eso la razón de ser de las virtudes éticas, pese a que por costumbre o por nacimiento puedan aparecer desde temprana edad, requiere también la virtud de la prudencia, ya que ella le permite al hombre deliberar correctamente acerca de las acciones que lo conducen a la felicidad.

Este mismo papel tiene la prudencia respecto a las virtudes intelectuales, pues aquellos que las desempeñan encuentran en la prudencia el buen tino para lograr sus fines. En este contexto, la prudencia es una virtud útil para deliberar sobre los medios necesarios que conducen a todo lo que se debe hacer. Así, por ejemplo, un médico no delibera si curará, un ingeniero si construirá, un orador si persuadirá y tampoco el político delibera sobre si legislará, pero todos ellos sí deben hacerlo para considerar el modo y los medios a través de los cuales poden alcanzar estas cosas, para lo cual la prudencia desempeña un papel fundamental (esto ayuda a clarificar lo que tres párrafos más arriba se indicaba sobre la diferencia entre la virtud de la prudencia y la virtud del arte, siendo la primera la disposición apropiada para las acción y la segunda para las producción). Aristóteles distingue varios tipos de prudencia (Cf. EN VI.8.1141b22-35) y destaca principalmente la utilidad y la importancia de la prudencia que se refiere a uno mismo y a la virtud ética, pues es la que indica en términos singulares lo bueno y lo malo para ser felices.

Con todo, puede suceder que una persona actúe y logre ser feliz sin que posea la virtud de la prudencia, lo cual no significa que sus acciones sean contrarias a la virtud. Aristóteles mismo no está comprometido en sostener que la felicidad sea un asunto de la mera razón. Lo que Aristóteles finalmente quiere indicar cuando introduce este segundo elemento formal de la definición de felicidad es que la razón es la encargada de indicar el blanco perfecto al que deben dirigirse las acciones humanas y que las actividades que nos acercan a la vida feliz son aquellas que parecen estar más próximas a lo que la razón ordena en cada situación, sea que se llegue a estas involucrándola o no. Ahora, para Aristóteles aquel que seguramente puede llegar a ser feliz, e incluso reencontrarla en caso de perderla, es la persona que siempre acompaña su accionar con la prudencia, ya que de otra manera el acceso a la felicidad se dará por accidente y puede ser algo inestable.

Aristóteles ofrece tres razones por las cuales es casi imposible ser felices si no se posee -en primera persona- la recta razón para orientar las acciones propias: 
primero, porque poseerla es algo bueno por sí mismo al ser una virtud del intelecto; segundo, porque no basta con desear ser felices sino que es necesario saber cómo llegar a serlo, para lo que es necesario realizar buenas elecciones y esto es algo que solo puede lograrse mediante la recta razón o prudencia, dice Aristóteles: "El deseo se refiere más al fin, la elección a los medios que conducen al fin [...] deseamos ser felices y así lo decimos, pero no suena bien decir que lo elegimos, porque la elección parece referirse a lo que depende de nosotros" (EN III.2.1111b28). Si bien el deseo dispone al ser humano a perseguir la felicidad, únicamente la prudencia le ayuda a alcanzarla apropiadamente $y$, en consecuencia, la necesita; dice Aristóteles: "El hombre lleva a cabo su obra mediante la prudencia y la virtud moral, porque la virtud moral hace recto el fin y la prudencia los medios que a él conducen" (EN VI.12.1144a7). Finalmente, la tercera razón consiste en que las virtudes del carácter son preservadas por la virtud intelectual de la prudencia, esto significa que para cualquier ser humano resulta muy difícil ser constante en la práctica de las virtudes morales sino puede, por sí mismo, ajustar el justo medio que las caracteriza. Cuando la prudencia está ausente las acciones que conducen a la felicidad se tornar episódicas y fortuitas, por eso Aristóteles afirma que "la virtud no es meramente la disposición conforme a la razón sino la que va acompañada de la recta razón, y la recta razón, tratándose de estas cosas es la prudencia" (EN VI.13.1144b24), afirmación que sería lo mismo que decir, sirviéndome aquí de un ejemplo para hacerla más clara, que también los animales salvajes y los niños pequeños que no han desarrollado la razón suelen actuar algunas veces como si fueran moderados o amables, acomodando sus acciones a lo que la recta razón podría indicarles, lo cual no significa que ellos la posean ni que puedan ser felices, pues sería necesario que sus acciones estén acompañadas siempre por esta.

En síntesis, la felicidad consiste en las actividades que conllevan una adecuada combinación entre la razón y el deseo, esta combinación solo se logra de la manera más acertada cuando actuamos de acuerdo con la virtud. Las virtudes del carácter nos inclinan a tener preferencias por determinados tipos de accionar, pero las complejidades que a veces envuelven la vida y las particularidades de nuestras circunstancias hacen difícil que logremos el blanco de lo que se supone que es la virtud. Alcanzar con certeza este blanco solo es posible a través de la prudencia o recta razón, la cual no produce acciones virtuosas pero nos ayuda a encontrar cuáles lo son, permitiéndonos idear los medios y tomar las decisiones necesarias para llevarlas a cabo7. Así lo dice Aristóteles en su Política "a cada individuo corresponde tanto de felicidad cuanto tenga de virtud, de prudencia, y actúe de acuerdo con ellas" (Pol VII.1.1323b12).

${ }^{7}$ Gerard J. Hughes explica mejor lo anterior cuando afirma: "We may feel inclined to be kind and generous, but until we have understood how to do that here and now, the virtuous inclination is not sharp enough. Yet, once we have understood what generosity and kindness require now, it is the action which exactly embodies that understanding which now becomes the content of our virtuous inclination" (2001, p. 107). 
Desde la perspectiva que aquí nos interesa, Alejandro Vigo (2006) Ilama la atención a los lectores y estudiosos de Aristóteles sobre algo que aparece en su excurso sobre la virtud y que a veces no es tenido lo suficientemente en cuenta, dejando escapar algo esencial para la comprensión de la racionalidad práctica que el filósofo atribuye al ejercicio de la prudencia. Consiste en la capacidad que Aristóteles reconoce a los agentes humanos de tener deseos que no están referidos solo a la inmediatez, como ocurre en el caso de los demás animales, sino que tienen en cuenta la perspectiva del tiempo. Este factor temporal dota a las acciones del hombre de un carácter más específico, basado en la posibilidad de acceder a un panorama de la acción que no se agota solo en el presente. En este sentido, un hombre hace un mejor uso de su racionalidad práctica y, en consecuencia, logra ser más prudente, cuando es capaz de ubicar la consecución de sus deseos en el registro temporal adecuado para darles trámite y logra conciliarlos con lo que su recta razón le indica.

Teniendo en cuenta entonces lo anterior, es válido concluir este apartado indicando que cuando Aristóteles sostiene que uno de los elementos formales de la felicidad consiste en ser una actividad que se realiza de acuerdo con la virtud, está intentando hacer el énfasis en que las actividades que contribuyen a la felicidad son aquellas en las que el hombre logra orientar sus deseos, además, sobre la base de una representación del conjunto de su vida como algo que se desarrolla en el tiempo y no exclusivamente en la inmediatez. La felicidad, en últimas, debe ser pensada para Aristóteles teniendo en mente la totalidad de una existencia y no la sucesión temporal de algunos episodios aislados.

\section{La felicidad es perfecta}

De acuerdo con Aristóteles, la perfección como elemento formal de la idea de felicidad estriba en el hecho de que todo aquello que pueda identificarse con ella debe tener el carácter de ser un bien último, es decir, algo que en la escala de los cosas mejores pueda ocupar el puesto más elevado. El criterio que utiliza Aristóteles para poder identificar las cosas que puedan ser estimadas a un nivel máximo -sean estas muchas, pocas o quizá una sola- consiste en que el ser humano se sienta inclinado a elegirlas por ellas mismas y nunca en función de otras cosas. La expresión que utiliza Aristóteles para identificarlas es teleion, cuyo significado es fin. El problema es que existen muchos fines parciales e intermedios y la felicidad no debe identificarse con ninguno de estos, pues lo que la hace algo superior a las demás cosas buenas es su calidad de ser fin perfecto (teleionteleiotaron). Cito a continuación las palabras del filósofo:

Puesto que parece que los fines son varios y algunos de estos los elegimos por otros, como la riqueza, las flautas y en general los instrumentos, es evidente que no todos son perfectos, pero lo mejor parece ser algo perfecto; de suerte que si solo hay un bien perfecto, ese será el que buscamos, y si hay varios, el más perfecto de ellos (EN I.7.1097a25). 
La perfección como elemento formal de la idea de felicidad parece algo improbable, pues a este nivel de la explicación aristotélica decir que la felicidad se elige siempre por sí misma no deja las cosas claras. Aristóteles recurre entonces a la siguiente aclaración de su argumento:

Llamamos más perfecto al que se persigue por sí mismo que al que se busca por otra cosa, y al que nunca se elige por otra cosa, más que a los que se eligen a la vez por sí mismos y por otro fin, y en general consideramos perfecto lo que se elige siempre por sí mismo y nunca por otra cosa (EN I.7.1097a30).

Lo anterior es una clasificación tripartita de los fines que indica (A) que existen unos que se persiguen en función de algo más, (B) que hay otros que se persiguen como fines en sí mismos y en función de algo más y, finalmente, (C) que están los que se persiguen solamente como fines en sí mismos. Los primeros (A) son parciales y tienen un carácter meramente instrumental; Aristóteles los identifica con el dinero y con los instrumentos en general. Los segundos (B) son intermedios, puesto que no están destinados a producir directamente la felicidad pero la favorecen; tales cosas son para Aristóteles -por ejemplo- el honor, el placer y el entendimiento. Los últimos (C), en cambio, sirven al bien específico de la felicidad porque están destinados directamente a producirla. No obstante, esto no clarifica todavía si la felicidad consiste en un solo fin del tipo (C) o si es posible incluir varios fines dentro de esta misma categoría.

Las cosas quizá pueden hacerse un poco más claras si nos referimos a dos afirmaciones que el filósofo presenta en las primeras páginas de sus dos obras éticas. La primera, de la Ética Nicomáquea, dice lo siguiente: "Si existe algún fin de nuestros actos que queramos por él mismo y los demás por este, y no elegimos todo por otra cosa, es evidente que ese fin será lo bueno y lo mejor. De otra manera se seguiría hasta el infinito, de suerte que el deseo sería vacío y vano, con el resultado de que sería inútil y sin sentido querer nada en absoluto" (EN I.2.1094a18-22). La segunda, de la Ética Eudemia, dice así: "puesto que la felicidad era algo perfecto, y una vida es perfecta o imperfecta, y lo mismo la virtud -pues una es completa y otra parcial- y dado que la actividad de las cosas imperfectas es imperfecta, la felicidad habrá de ser la actividad de una vida perfecta conforme a una virtud perfecta" (EE II.11218a31-34).

De acuerdo a lo que dejan colegir estas dos últimas citas podemos derivar lo que sigue: en vista de que existe un fin para toda actividad y dada la posibilidad de articular algunos fines en estructuras de actividades más comprensivas y complejas, en las que estos sirven de medios o condiciones para su obtención, suponer que todo fin ha de ser querido siempre como medio para otro fin nos llevaría a la indeseable consecuencia de que nuestro accionar respondería al de unos autómatas que trabajan día a día sin un propósito o motivación final, con lo que nuestro deseo sería vacío y vano. Ha de existir entonces algún fin (entre los 
fines) que nunca queramos lograr más que por la mera satisfacción de alcanzarlo y este habrá de ser llamado felicidad; sea identificado -cuantitativamente- con uno o con varios fines que ocupen al tiempo o alternativamente la categoría de los fines (C). Ahora, sobre la base de los anteriores dos elementos formales que se han desarrollado, el horizonte que se abre a la felicidad como fin último o perfecto ha de ser uno que no solo se logre en el momento preciso y presente con la realización de cada acción en singular, sino que apunte también a la de un espacio más amplio de vida, como actividad abarcante que se expresa en un accionar temporalmente extendido. Solo así podría entenderse la felicidad como un fin perfecto, más aún si tomamos como indicios las últimas palabras del filósofo que han quedado consignadas al final del párrafo anterior: la felicidad habrá de ser la actividad de una vida perfecta conforme a una virtud perfecta.

\section{La felicidad es auto-suficiente}

Las palabras de Anthony Kenny son un excelente punto de partida para indicar qué sentido tiene para Aristóteles este cuarto elemento formal de su definición de felicidad: "No human condition will achieve the goal of self-sufficiency; none the less, [for Aristotle] self-sufficiency provides an ideal norm by which to judge the merit of candidates for eudaimonía" (1992, p. 36). La idea de la autosuficiencia es uno de esos elementos teóricos a los que Aristóteles le otorga más relevancia en sus escritos éticos, pero también es uno frente a los que no ofrece una explicación clara. Esto ha incitado a muchos intérpretes a proponer diferentes concepciones del mismo, por desgracia para nada homólogas porque tienden a priorizar algunas de las elaboraciones del filósofo sobre otras. La variedad en las interpretaciones se debe aquí al autor mismo, debido a que constantemente hace oscilar sus elaboraciones entre una idea de la autosuficiencia basada en los recursos y otra basada en las actividades virtuosas. Esto se nota con particular relevancia en el apartado de la Ética Nicómaco en donde el filósofo habla por primera vez de la autosuficiencia y la felicidad, describiéndola de la siguiente manera:

Estimamos auto-suficiente lo que por sí solo hace deseable la vida y no necesita de nada; y pensamos que tal es la felicidad. Es lo más deseable de todo, aun sin añadirle nada; pero es evidente que resulta más deseable si se le añade el más pequeño de los bienes, pues lo agregado resulta una superabundancia de bienes, y entre los bienes, el mayor es siempre más deseable (EN I.7.1097b14-20).

Existen dos bandos de estudiosos que se disputan la mejor interpretación de la idea de autosuficiencia con relación a la felicidad para Aristóteles, ambos parten de la equivocidad que genera esta cita. Uno de los bandos ha sido liderado por la lectura del especialista en filosofía griega antigua John Lloyd Ackrill, quien denominó su enfoque como 'inclusivo'; Ackrill consideraba que la idea de autosuficiencia que exhibe Aristóteles a lo largo de su obra ética da a entender 
que la felicidad está constituida por una pluralidad de bienes y actividades. El otro bando es liderado por Richard Kraut, quien considera que la felicidad es algo autosuficiente para Aristóteles porque entre un número amplio de actividades que conducen a la virtud, solamente una de ellas ha de ser superior a las demás, básicamente porque su realización dota de sentido al resto de las actividades. Kraut ha llamado a su enfoque como 'dominante'.

Presentaré a continuación los rasgos más destacados de ambos enfoques e indicaré una postura intermedia que veo plausible asumir tomando como ejemplo las palabras de Céfalo respecto a la riqueza, tal como presenta Platón la opinión de este personaje en su diálogo la República. La idea es proponer una alternativa de interpretación que se corresponda a la descripción formal que Aristóteles hace de la felicidad.

Comenzaré con el enfoque inclusivo. Ackrill elabora la columna vertebral de su argumento sosteniendo que no debería confinarse la filosofía aristotélica a una lógica teleológica, que más que un punto de referencia para entender sus ideas constituye un modo de hablar enraizado en la concepción cosmológica que caracterizó a los griegos. Cuando esto no es tenido en cuenta, opina Ackrill, suele perderse mucho de lo que Aristóteles está intentando decir en sus libros de filosofía práctica (1999, p. 62). El lenguaje teleológico en Aristóteles conduce a la dificultad de que todas las acciones morales queden subordinadas a la felicidad y justifica que los seres humanos actúen movidos principalmente por principios egoístas que no toman en consideración debidamente a los otros. Esta es una grave inconsistencia para Ackrill porque desemboca en la justificación de algunas acciones inmorales en pro de la felicidad.

Un punto importante en el que Ackrill se apoya para favorecer su lectura inclusiva de Aristóteles consiste en que el término eudaimonía no debe ser traducido indiferentemente como felicidad (sustantivo singular) sino como 'vida lograda' o 'el mejor modo de vida', pues de esta manera se es más coherente con lo que el filósofo griego intenta demostrar a lo largo de sus obras éticas, a saber: que la felicidad da cabida a una multiplicidad de cosas. Dice Ackrill: "The word eudaimonía has a force not at all like "happiness", "comfort", or "pleasure", but more like "the best possible life" (where "best" has not a narrowly moral sense). This is why there can be plenty of disagreement as to what form of life is eudaimonía, but no disagreement that eudaimonía is what we all want" (1999, pp. 66-67).

Frente a la cita de Aristóteles consignada al inicio de esta sección, Ackrill interpreta que lo que el estagirita está intentando plantear es que la felicidad es genuinamente autosuficiente en la medida en que incluye todo lo que es deseable en sí mismo, dentro de lo cual no solo están las actividades sino también los estados y las posesiones. Ackrill le da fuerza a su argumento a partir de la última parte de esta cita, en la que aparecen consignadas las siguientes palabras del 
filósofo griego: "es evidente que [la felicidad] resulta más deseable si se le añade el más pequeño de los bienes, pues lo agregado resulta una superabundancia de bienes, y entre los bienes, el mayor es siempre más deseable".

Quienes se inclinan como Ackrill hacia una interpretación inclusiva de la felicidad, insisten en que para Aristóteles no hay un concepto claro y definido de lo que esta consiste, dicen que continuamente el filósofo va de aquí para allá intentando abarcar todo el fenómeno de la felicidad y va integrando alternativamente consideraciones sobre los bienes exteriores, se pregunta por el papel de la suerte y la gracia de los dioses en el logro de la felicidad y destaca especialmente el papel de los amigos y de la comunidad para que los seres humanos logren ser felices. No ven gratuito que Aristóteles tipifique la autarquía como contraría a una vida solitaria e insisten en que el filósofo afirma que el hombre es una realidad social justo unas líneas antes de introducir el pasaje problemático en donde él explica cómo entiende el elemento formal de la autarquía ${ }^{8}$. Consideran que la posición que Aristóteles asume en la última parte de su Ética Nicomáquea, en donde favorece decididamente la actividad filosófica como prototipo de la vida feliz, es un intento de ejemplificar los rasgos de un estilo de vida cercano al ideal de vida del propio filósofo griego y cuestionan abiertamente que atribuya tanta importancia a la vida política como un modelo de vida inclusiva.

En síntesis, los intérpretes que suscriben el punto de vista inclusivo mantienen que aquellos que afirman que para Aristóteles la felicidad consiste únicamente en una actividad suprema de acuerdo con la virtud, que debe ser elegida por encima de todo lo demás, asumen una lectura implausible con la que seguramente el filósofo griego no estaría dispuesto a comprometerse con toda la seriedad del caso.

Ahora bien, Richard Kraut enfatiza una posición contraria y la expresa del siguiente modo: "Aristotle thinks that a well-lived human life will be endowed whit a rich variety of goods, but that nonetheless it will have a single focus" (1999, p. 79). Para él Aristóteles es claro al afirmar que la felicidad es en esencia una actividad y no son los bienes ni los estados (héxis). La actividad virtuosa es lo que está en el tope de la felicidad para Kraut, lo cual no significa que el ser humano no necesite de recursos para llegar a desarrollar esta actividad. Para Kraut, Aristóteles sostiene que existen bienes y estados que son deseables en sí mismos pero de manera subordinada, es decir, se desean porque conducen a la felicidad y no por otra cosa (1999, p. 83).

\footnotetext{
${ }_{8}$ Pocos renglones antes de la cita problemática consignada al inicio de esta sección Aristóteles escribe: "Parece que también ocurre lo mismo con la autarquía, pues el bien perfecto parece ser suficiente. Pero no entendemos por suficiencia el vivir para sí solo una vida solitaria, sino también para los padres y los hijos y la mujer, y en general para los amigos y conciudadanos, pues el hombre es una realidad social" (EN I.7.1097b7-11).
} 
La posición de la idea de felicidad dominante de Kraut se puede comprender de la siguiente manera: si A es un bien y B es un bien diferente, es mucho más deseable tener A y B que tener uno solo de los dos, no obstante, si B se busca por el bien de A (es decir, para hacer de $\mathrm{A}$ un bien mucho mejor) es prioritario tener $\mathrm{A}$ que tener $\mathrm{B}$, pues este último solo adquiere sentido y se convierte en un bien cuando existe el primero. En síntesis, Kraut considera que la actividad según la virtud tiene un efecto causal en las demás actividades y hace que los bienes y estados entren a ser considerados como partes esenciales de la felicidad.

Para hacer frente al difícil pasaje de Aristóteles que he citado al inicio de esta sección, Kraut insiste en que el filósofo griego no está hablando de la virtud cuando afirma que el bien mayor es más autosuficiente cuando se le suma el más pequeño de los bienes, sino que está intentando decir que un bien se hace mejor cuando se le suma cualquier otro bien. El hecho de que Aristóteles indique un par de caracteres antes que el bien mayor es lo más deseable, aun sin añadírsele nada, y que este es el rasgo más básico de todo lo que es autosuficiente, es un signo claro que favorece su interpretación, según explica Kraut, a quien cito puntualmente a continuación:

The point Aristotle is making in the passage we are examining is simply that anyone who thinks of virtue (or any other good) as being susceptible to this kind of improvement is not identifying it whit happiness, but is merely naming one component of happiness that can be improved upon by being supplemented by other goods. If one were to take this view of virtuous activity, then one would not say of it, "Taken by itself [it] makes life choiceworthy and in need nothing" (1999, p.85).

El punto en el que quiere insistir Kraut es que la felicidad es completamente autosuficiente en tanto actividad virtuosa y que los bienes y los estados no son esenciales para otorgarle a esta idea un mayor peso del que por sí mismo tiene.

Existe una tercera postura frente al elemento de la autosuficiencia de la felicidad que puede decirse que es intermedia entre la posición de Ackrill y la de Kraut, según la cual, para Aristóteles, las actividades de acuerdo con la virtud no son causa eficiente de que las demás cosas (bienes, estados y demás) adquieran sentido en orden a la felicidad, sino que simplemente explican por qué razón son más apreciadas cuando la actividad según la virtud está presente. Un ejemplo para ilustrar este punto se encuentra en el diálogo la República de Platón, cuando Sócrates pregunta al anciano Céfalo ¿̇cuál es el mayor beneficio de haber poseído una gran fortuna? Frente a la cual este responde:

La posesión de riquezas contribuye en gran parte a no engañar ni mentir involuntariamente, así como a no adeudar sacrificios a un dios o dinero a un hombre, y por consiguiente, a no marcharse con temores hacia el Hades. Las riquezas, por supuesto, tienen muchas otras ventajas; pero comparando unas con otras, Sócrates, no consideraría a las mencionadas como las de menor importancia para que la riqueza sea de máxima utilidad a un hombre virtuoso (Rep. I.331b). 
Esta tercera posición sobre el elemento formal de la autosuficiencia se mantiene a medio camino entre la idea de que la felicidad está cimentada solamente en una actividad que dota de sentido a las demás y la idea de que está constituida por una pluralidad de bienes y actividades. Se distancia específicamente de la posición defendida por Kraut porque indica una ruta diferente y opuesta para lograr que la felicidad tenga su génesis en los seres humanos únicamente a partir de las actividades virtuosas. Se distingue de la posición de Ackrill porque no pone a los bienes ni a los estados en el mismo nivel de las actividades virtuosas, sino que indica como necesario algunos elementos materiales para que las actividades virtuosas puedan emerger.

El hecho importante que esta tercera posición señala es que para Aristóteles la felicidad, para que pueda ser posible en este mundo, debe contar con que los seres humanos somos criaturas espacio temporalmente situadas y tenemos la urgencia de satisfacer ciertas necesidades materiales propias de nuestra condición. De este modo, que Aristóteles incluya dentro de su descripción formal de la felicidad la idea de la autosuficiencia y no dude en identificarla con ciertas condiciones materiales necesarias para la existencia humana en este mundo, constituye un hecho altamente meritorio que muestra cómo ella es un deseo que nos vincula directamente con todo nuestro entorno. Las condiciones materiales de los hombres constituyen un requisito instrumental que hace posible pensar la idea de felicidad para Aristóteles, lo que se revela en el libro uno de su Ética Nicomáquea cuando afirmar:

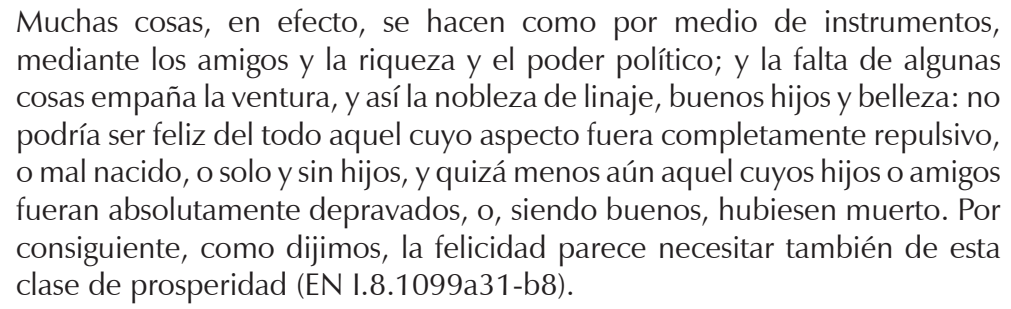

Ahora bien, si entramos a considerar algunos lugares en donde el filósofo tematiza la cantidad de bienes que son necesarios para una vida feliz, encontremos que reconoce la existencia de tres clases de bienes: los externos, los del cuerpo y los del alma, siendo los últimos los más importantes debido a que son primarios y más propiamente bienes (Cf. EN I.8.1098b13). En la Ética Eudemia Aristóteles señala esto con mayor precisión y dice directamente que todos los bienes que existen se pueden contar simplemente en número de dos: los externos y los internos al alma, y a continuación explica que los bienes del alma conllevan en sí mismos la acción humana, mientras que los externos se reducen a meras posesiones que no participan en sí mismos de la existencia de los hombres y pueden ser incluso independientes a estos (Cf. EE II.1.1218b29). En la Política insiste en que 
la felicidad se acrecienta cuanto mayor sea la cantidad de bienes del alma que se posean e indica que "nadie podría llamar feliz al que no participa en absoluto de la fortaleza, ni la templanza, ni la justicia, ni la prudencia", bienes más preciosos y deseables que la riqueza o la salud del cuerpo (Cf. Pol VII.1.1323a4, b8-9).

Si bien es cierto que Aristóteles atribuye una superioridad relativa a los bienes del alma respecto a los bienes del cuerpo y a los exteriores, en ningún momento va a negar que las tres clases bienes deban estar presentes en la vida del hombre feliz. Como era de esperar, los bienes del alma son los principales porque se traducen en actividades de acuerdo con la virtud y son la clase de bienes que se acomodan, con toda precisión, a las características formales de su definición de felicidad. La dificultad de la lectura material estriba en el hecho de que existe un desacuerdo respecto a la cantidad de los bienes exteriores y los del cuerpo que son necesarios para alcanzarla, bienes que son fundamentales en la medida en que subsidian las actividades virtuosas, pues "es claro que la felicidad necesita de los bienes exteriores [y los del cuerpo] pues es imposible o no es fácil hacer el bien cuando se está desprovisto de recursos" (EN I.8.1099a31-33).

En el artículo uno del libro séptimo de la Política, Aristóteles presenta de forma sintética tres tipos de argumentos que permiten hacernos una idea sobre la cantidad de bienes exteriores y del cuerpo que necesita un hombre para ser feliz; el primero es un argumento empírico, el segundo uno racional y en el tercero Aristóteles pone por testigo a la divinidad. A continuación presentaré cada uno de estos argumentos, atemperándolos de vez en cuando con otras elaboraciones del filósofo que aparecen en sus obras éticas.

1. El argumento empírico: Para Aristóteles es posible llegar a una convicción sobre la cantidad de bienes necesarios para la felicidad si se recurre directamente a los hechos. De acuerdo con este argumento:

[...] vemos que no se adquieren y se conservan las virtudes por medio de los bienes exteriores ${ }^{9}$, sino estos por medio de aquellas, y que la vida feliz [...], corresponde a quienes están adornados con los dones del carácter y de la inteligencia en grado sumo, aunque estén moderadamente favorecidos en la posesión de bienes exteriores, más que a los que poseen estos bienes por encima de lo necesario, pero están faltos de aquellos (Pol VII.1.1323b1).

Para Aristóteles la felicidad la constituye una moderada posesión de bienes exteriores, no su superabundancia. La felicidad no podría ser posible si dependiera de algo tan fluctuante como las posesiones materiales o si solamente recayera en la vulnerabilidad de los estados físicos. La felicidad depende sobretodo de los dones del carácter y de la inteligencia, pero también necesita de circunstancias físicas y materiales favorables. Aristóteles no cree que el hombre feliz sea un mago de la

\footnotetext{
${ }^{9}$ Las cursivas son mías.
} 
escases, capaz de obtener de la nada todo lo necesario para vivir, pero tampoco cree que sea el rey de la abundancia. La idea básica se encuentra en el hecho de que las personas que saben actuar de acuerdo con la virtud, no necesitan de una cantidad exagerada de los bienes del cuerpo y exteriores, sino que son capaces de actuar de buena manera incluso en circunstancias desfavorables o de escasez. Con todo y esto, para Aristóteles existe una distancia real entre ser bueno y ser feliz que no debe olvidarse, pues "el hombre bueno puede hacer buen uso de la pobreza, la enfermedad y los demás infortunios, pero la felicidad consiste en sus contrarios" (Pol VII.13.1332a8); los bienes del cuerpo y los exteriores son necesarios para que la vida sea tolerablemente estable frente al mundo, pues "muchas cosas, en efecto, se hacen, como por medio de instrumentos, mediante los amigos y la riqueza" (EN 1.8.1099b2-4). Aristóteles nunca ofrece un criterio cuantitativo exacto para juzgar con precisión la cantidad de bienes exteriores y del cuerpo que un hombre necesita para ser feliz, sin embargo, afirma constantemente que los hechos son un buen recurso para demostrarlo; en el libro diez de la Ética Nicómaco se observa de nuevo esta actitud del filósofo cuando afirma: "en efecto, uno puede, con recursos moderados, practicar la virtud (esto puede verse claramente ${ }^{10}$ considerando que los simples particulares llevan a cabo acciones virtuosas tanto como los poderosos, incluso más); bastará, pues, disponer de bienes exteriores en esa medida, ya que será feliz la vida del que actúe de acuerdo con la virtud" (X.8.1179a9).

2. El argumento racional: Aristóteles indica que la razón nos permite comprender con facilidad cuánta cantidad necesitamos de los bienes exteriores y del cuerpo. "En efecto, [si lo examinamos racionalmente] los bienes exteriores tienen un límite, como cualquier instrumento (todo lo que sea útil sirve para una cosa determinada); y su exceso, necesariamente, o perjudica, o no sirve de nada a los que los poseen; en cambio, cada uno de los bienes relativos al alma, cuanto más abundan más útiles son" (Pol VII.1.1323b9). Aristóteles ve como un estorbo la abundancia de bienes a la hora de alcanzar la felicidad. Los cuidados que implica administrar muchas posesiones pueden privar a los hombres de realizar acciones virtuosas, pues existe el riesgo de querer permanecer más inactivo con tal de conservar la cantidad de las cosas que se poseen. Para el estagirita, siguiendo a Solón, el hombre feliz es quien posee una cantidad moderada de bienes exteriores y no se ve atado ni impedido por ellos para actuar como se debe (Cf. EN 1179a911), no es un extremo un dadivoso pero tampoco alguien que "amarra" lo que posee por el simple miedo a perderlo. El hombre que sabe acceder a la felicidad comprende que la actuación implica un grado considerable de vulnerabilidad frente a lo que se tiene, pero reconoce que el quid de la vida no está en retener y acumular sino en usar las cosas como instrumentos para las acciones.

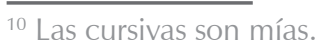


3. El testimonio de la divinidad: Aristóteles finalmente pone por testigo a la divinidad para afirmar que la vida feliz no lo es en modo alguno por los bienes exteriores o los estados, como tampoco lo es por la suerte, ya que ni los bienes, ni los estados, ni la suerte son los que actúan sino que lo hacen los hombres. Estas son cosas que simplemente acompañan la acción pero no actúan y "es imposible que le salgan las cosas a los que no obran" (Pol VII.1.1323b12). Para Aristóteles "los dioses poseen la máxima bienaventuranza y felicidad" (EN X.8.1178b9) y es absurdo que ellos tengan dinero o cosas semejantes (Cf. EN X.8.1178b15), la vida de los hombres es más feliz en la medida en que se acerca a la de los dioses, quienes solo se afanan por las actividades que involucran al intelecto, especialmente por la contemplación, para la cual los bienes necesarios son pocos. "Sin embargo -dice Aristóteles- el hombre contemplativo, por ser hombre ly no Dios], tendrá necesidad del bienestar externo, ya que nuestra naturaleza no se basta a sí misma para la contemplación, sino que necesita de la salud del cuerpo, del alimento y de los demás cuidados. Pero no se ha de pensar, [...] que los necesita en gran número y calidad" (EN X.8.1178a33). Como sugiere Martha Nussbaum, Aristóteles se cuida en decretar categóricamente que lo único importante en la vida es lo que se encuentra sometido completamente al control de hombres aislados (Cf. 2004, p. 441). El contenido de la felicidad aristotélica no es solo el contento y la satisfacción sin apuro, sino también el disfrute de la vida en toda su magnitud y plenitud.

Es necesario asumir entonces como conclusión que la felicidad es autosuficiente para Aristóteles en la medida en que dispone de ciertas condiciones materiales indispensables para el desarrollo de la actividad humana en el mundo. Antes de negar la vulnerabilidad a las circunstancias externas y necesarias para la vida, Aristóteles reflexiona abiertamente sobre ellas y reconoce al hombre como un ser necesitado de compañía y recursos. Sin embargo, siempre va ser insistente en esto: "en modo alguno se deben seguir las vicisitudes de la fortuna; porque no estriba en ellas el bien ni el mal, aunque la vida humana necesita de ellas, como dijimos; las que determinan la felicidad son las actividades de acuerdo con la virtud, y las contrarias, lo contrario" (EN I.10.1100b7-11).

\section{Proposiciones sobre la idea de la facilidad como un fin no comprensivo en Aristóteles}

Todo lo que he expuesto hasta acá es un intento de resaltar lo que Aristóteles dice sobre la felicidad en el registro de lo que podríamos llamar la interpretación no comprensiva, es decir, sin suscribir la posición que él adoptó al identificar la vida contemplativa de los filósofos y la experiencia política en la polis griega como los prototipos idóneos frente a su descripción de los elementos formales de la felicidad. La predilección del filósofo griego por estos dos modos de materializar la felicidad y el elevado protagonismo que suele otorgárseles, deja en ciernes 
rendimientos importantes que pueden sustraerse a su idea de felicidad y son susceptibles de ser aplicados en sociedades contemporáneas en condiciones de pluralismo, es decir, en donde sus ciudadanos llevan distintos modos de vida y buscan diferentes metas, y en donde existen distintos grupos de interés que promueven variadas concepciones sobre cómo materializar lo bueno, lo que impide la cristalización de una concepción de la felicidad signada por parámetros fuertemente delimitados. De aquí el interés por resaltar los elementos formales o estructurales de la felicidad para Aristóteles, separados de los materiales o asociados a los dos prototipos de vida que él propone.

En este contexto, las proposiciones que presento a continuación son un intento de brindar elementos de juicio y reflexión para la búsqueda personal de la felicidad que gran parte del pensamiento político contemporáneo empuja con fuerza sobre el individuo -dadas las condiciones de pluralismo ya señaladas-, y pueden ser de utilidad para seres humanos, con diversos intereses y filiaciones doctrinales, que habitan, reflexionan y buscan su felicidad en sociedades contemporáneas en condiciones de pluralismo.

I. Para Aristóteles la felicidad está en la realización de la actividad, en su desarrollo, no en el estado que da origen a la actividad ni en la racionalidad práctica (o prudencia) que la orienta o motiva. La felicidad es virtud en ejecución, no acontece cuando estamos planeando o pensando hacer algo, sino cuando estamos ejecutando - de facto- una facultad. Con todo, es claro que para Aristóteles se necesita de la virtud para ser felices, pues esta no surge espontáneamente sino que precisa de las condiciones que la hagan posible, a saber: un núcleo subyacente de racionalidad práctica bien templado y acerado por la experiencia y cuya expresión natural es la actividad excelente ${ }^{11}$.

II. Ahora bien, la idea de felicidad para Aristóteles no solo hace referencia a actividades aisladas que emergen por el influjo momentáneo de las facultades racionales, sino también y principalmente al ejercicio pleno y constante de dichas facultades, que se traduce en actividades que se repiten en un espacio y en un tiempo determinado.

III. Por consiguiente, es preferible planificar las actividades y, de ser posible, periodos enteros de la vida. Planificar la vida -en la medida en que se puedafacilita que la felicidad sea accesible de forma más efectiva.

IV. La perspectiva del espacio-tiempo es un elemento valioso para comprender la concepción de la felicidad en Aristóteles, como ya dejé indicado al final del acápite sobre la virtud apoyándome en la sugerente apreciación de Alejandro Vigo. Las dificultades para lograr que la felicidad sea algo accesible y constante para el ser humano, se encuentran en que muchas veces este no elije las

${ }_{11}$ Para ampliaciones al respecto ir a (Nussbaum, 2004, p. 432). 
actividades que acarrean un bien más valioso sino que considera tales a las que se desprende de la actividad más próxima. Esto sucede por incurrir en indulgencias sensuales y momentáneas que menoscaban el carácter perfecto que Aristóteles atribuye a la felicidad.

V. Ahora bien, Aristóteles no considera que la felicidad sea contraria a los placeres, pues estos y las actividades Ilevan una existencia correlativa. Sin embargo, la felicidad no consiste expresamente en un tipo particular de los mismos, sino en que todas las actividades a las que ellos acompañan estén orientadas por la virtud. Algo en lo que hay que insistir frente a esto último es en el rol motivador del deseo, principio natural de la acción en los seres humanos.

VI. La idea de Aristóteles sobre la felicidad como fin perfecto (último) de la acción es algo que no debería desestimarse; ya que considerarla así, en el contexto general de la filosofía práctica, podría fungir como criterio-árbitro o criterioevaluativo para cuando, en el marco de una teoría práctico-normativa en concreto, exista un conflicto entre principios fundamentales que haga difícil determinar el rumbo preferible de acción. Para esto han de elaborarse las debidas aclaraciones y precisiones sobre los contextos en los que sería aplicable la felicidad como criterio al interior de la teoría en concreto, lo cual seguramente la dotaría de mayor eficiencia.

VII. Es posible afirmar que los elementos formales que he presentado a lo largo de este capítulo, como constitutivos de la idea de felicidad en Aristóteles, funcionan como criterios normativos de la misma, adheridos a la dimensión espacio-temporal que envuelve a la vida humana y junto a las condiciones empíricas necesarias para su subsistencia (esto último tal como dejé indicado al abordar el elemento de la autosuficiencia) $\varphi$

\section{Referencias}

Ackrill, J.L. (1999). Aristotle on eudaimonia. En Nancy Sherman, (Ed.), Aristotle's Ethics. Critical Essays, (57-58). United State Of America: Rowman \& Littlefield Publishers.

Aristóteles (1994). La Política. Traducción y notas de Manuela García Valdés. Madrid: Gredos.

Aristóteles (2002). Ética Eudemia. Traducción y notas de Carlos Megino Rodríguez. Madrid: Alianza.

Aristóteles (2009). Ética Nicomáquea. Introducción, traducción y notas de Julián Marías y María Araujo. Madrid: Centro de estudios políticos y Democráticos. 
Bobbio, B. (2003). Teoría general de la política. Madrid: Trotta.

Chantraine, P. (1977). Le dictionnaire étymologique de la langue grecque. Histoire des mots. París: Klincksieck.

Hughes, G. (2001). Aristotle on Ethics. London: Routledge.

Kenny, A. (1992). Aristotle on the perfect life. Oxford: Oxford University Press.

Kraut, R. (1999). Aristotle on the human good: An overview. In N. Sherman (Ed.), Aristotles's Ethics. United States of America: Rowman \& Littlefield Publishers.

Luri, G. (2011). Introducción al vocabulario de Platón. Sevilla: Fundación ECOEM.

Nussbaum, M. (2004). La fragilidad del bien. Madrid: Machado Libros S.A.

Pakaluk, M. (2005). Aristotle's Nicomachean Ethics an introduction. Cambridge: Cambridge University Press.

Platón (1998). Diálogos, La República, Tomo IV. Introducción, traducción y notas por Conrado Eggers Lan. Madrid: Gredos.

Snell, B. (2007). El descubrimiento del espíritu. Barcelona: Acantilado.

Vigo, A. (2006). Aristóteles. Una introducción. Santiago de Chile: IES. 